\title{
STUDIES OF AMNIOTIC MEMBRANES
}

\author{
A. LAUFER, W. Z. POLISHUK, J. BOXER AND R. GANZFRIED \\ Departments of Pathology, Obstetrics and Gynaecology, Rothschild Hadassah University \\ Hospital, and the Hebrew University-Hadassah Medical School, Jerusalem, and \\ Sol Gold Laboratory, Rothschild Hospital, Haifa, Israel
}

(Received 10th February 1966)

Summary. Tensile strength, mucopolysaccharide deposits, hexosamine and collagen contents of membranes were studied in mature and premature deliveries.

Membrane tensile strength, which was found to vary between 50 and $500 \mathrm{~g} / \mathrm{cm}$, is significantly higher in membranes of premature deliveries as compared to mature deliveries. An inverse correlation between tensile strength and foetal weight was observed.

Acid mucopolysaccharides are more frequently and abundantly found in membranes as pregnancy progresses. A similar tendency was found with hexosamine content of the membranes. Collagen values did not vary significantly in mature and premature deliveries.

A significant correlation was found between the reduction of collagenhexosamine ratio and reduction in membrane tensile strength.

The possibility that this change is related to placental dysfunction and associated with hormonal imbalance has been discussed.

\section{INTRODUCTION}

Little is known of the etiology of premature rupture of membranes. It has been reported as more frequent in primiparae and in urban rather than rural populations (Halban \& Seitz, 1925). In over $30 \%$ of cases spontaneous premature rupture of the membranes precedes the onset of premature labour (Bourne, 1962; Javert, 1957). The frequency varies in different ethnic groups. In Israel, it was found to occur in $26 \%$ of women of European origin as compared to $17.9 \%$ of Oriental and $12.1 \%$ of Yemenite origin (Polishuk, Kohane \& Wisnitzer, 1965).

The incidence of premature rupture of membranes is variously reported, by different authors (Kaplan, 1963), to be between $2 \%$ and $22.3 \%$ of deliveries, but the lack of a uniform definition of this condition makes comparisons difficult. The definition proposed by Halban \& Seitz (1925), namely, the rupture of membranes before the onset of uterine contractions or cervical dilatation during the last trimester of pregnancy, is the most logical and inclusive and has been adopted by us in our studies.

Premature rupture of membranes is evidently associated with a weakening in the tensile strength in a limited area. Foetal membranes do not have uniform strength (Polishuk, Ben-Sira \& Kohane, 1965), variations in tensile strength 
are much greater and more frequent in membranes from mature deliveries than in cases of prematurity. Areas of 50 to $90 \mathrm{~g} / \mathrm{cm}$ tensile strength were found in membranes whose average tensile strength ranged between 500 and 700 $\mathrm{g} / \mathrm{cm}$.

To understand the mechanism underlying the weakening of foetal membrane tensile strength, it is clearly important to know more about their histological and chemical characteristics. This paper reports some of our results on the physical properties, histological and chemical studies in foetal membrane in various stages of pregnancy. The histological and chemical studies were limited to the amnion layer, as this part of the membrane accounts for most of its tensile strength (Polishuk, Kohane \& Peranio, 1962).

\section{MATERIALS AND METHODS}

Amniotic membranes stripped shortly after delivery were obtained from 382 mature and premature deliveries, birth weights varying between 600 and $4500 \mathrm{~g}$. Both normal and abnormal births were included.

The amnii of the first group of 250 cases were studied for tensile strength by the method described previously (Polishuk et al., 1962). From these, two areas were chosen for histological examination, from near the umbilical cord and from the margin of the tear.

In a second group of fifty cases, a similar study was made as well as chemical determination of hexosamine in the remainder of the membrane.

In a third group of eighty-two cases, seven to ten areas of $21 \mathrm{~mm}$ in diameter were obtained from each membrane. These included three to four areas near the placental border, three to four areas from the border of the tear and one to two areas from the mid-portion of the membrane. These areas were studied for tensile strength, following which one portion of each was taken for histological examination and the remainder for determinations of hexosamine and hydroxyproline.

\section{Tensile strength}

This was studied by determining the bursting point of the membranes under different pressures and has been described elsewhere (Polishuk et al., 1962; Polishuk, Kohane \& Hadar, 1964).

\section{Histological studies}

The material was fixed in $10 \%$ formalin and stained with haematoxylin and eosin, van Gieson, PAs stain, colloidal iron for acid mucopolysaccharides, Reinhart-Abul Hag, and Laidlaw's reticulum stain.

\section{Hexasamines}

These were determined in the acetone dried amnion of eighty-seven cases. These included nineteen premature and sixty-eight mature membranes. Amniotic membranes were washed with normal saline until free from blood and then washed twice with distilled water. The washed membranes were air dried, ground and extracted overnight with acetone, dried again and left in the desiccator until they attained constant weight. The dried amniotic 
membranes were hydrolysed with $2 \mathrm{~N} \mathrm{HCl}$ at $130^{\circ} \mathrm{G}$ in closed vessels, the hydrolysate neutralized and hexosamine determined by a modified method of Boas (1953).

\section{Collagen}

This was studied in sixty-four membranes, including forty mature and twenty-four premature membranes. The acetone dried amnii were hydrolysed with $6 \mathrm{~N} \mathrm{HCl}$ at $130^{\circ} \mathrm{C}$ in closed ampoules, neutralized and an aliquot was used for the determination of hydroxyproline by the method of Woessner (1961). The collagen content was calculated by multiplying the hydroxyproline content by the factor 7.46 (Stegemann, 1958).

\section{RESULTS}

Tensile strength

Membrane tensile strength varied between 50 and $500 \mathrm{~g} / \mathrm{cm}$ and was higher in premature than in mature deliveries. While membranes of mature deliveries had an average tensile strength of $207 \mathrm{~g} / \mathrm{cm}$, that of premature deliveries was $299 \mathrm{~g} / \mathrm{cm}$. There was an inverse correlation between foetal weight and specific tensile strength up to a weight of $3750 \mathrm{~g}$, after which average tensile strengths remained more or less constant. When tensile strengths were measured in small portions of membranes, $21 \mathrm{~mm}$ in diameter as compared with $54 \mathrm{~mm}$ in diameter, the variations were greater and more frequent in mature than in premature births.

\section{Histologic changes}

The pertinent findings were in the subepithelial layer of the amnion which was thin in some areas alternating with thicker and homogeneous eosinophilic staining areas. PAS stain was observed only in the basal membrane of the epithelial layer (Pl. I, Fig. 1). Coarse and fine granules in the amniotic epithelium were present.

Colloidal iron stain (acid mucopolysaccharides) revealed marked variations in staining intensity of the subepithelial layer, between intense and absent staining in the same section (Pl. 1, Fig. 2). The intensity of staining was frequently associated with a thickening of the subepithelial layer. Acid mucopolysaccharides were observed in both epithelial and subepithelial layers, but no correlation was found between the presence or amount of this material in the two layers. There were, however, membranes with abundant collagen fibres but no acid mucopolysaccharides, while in others all the areas examined revealed abundant deposits (Pl. 1, Figs. 3 and 4). In membranes from premature deliveries areas with positive acid mucopolysaccharide staining were significantly fewer than in mature membranes. Of 245 areas from membranes from mature deliveries $66 \%$ showed mucopolysaccharide deposits of varying intensity. Of sixty-two areas from premature deliveries only $38 \%$ were positive for colloidal iron. It thus appears that the amount of deposition of acid mucopolysaccharides increases in intensity with the rise in foetal weight.

The collagen fibres varied in thickness and length. Some were thin, short and wavy, others were thick and elongated. Reticulum fibres varied in size and shape. 


\section{Hexosamine content}

The hexosamine content of the amniotic membrane dry powder showed a mean of $1.3 \mathrm{~g} / 100 \mathrm{ml}$ and a range of 0.76 to $1.89 \mathrm{~g} / 100 \mathrm{ml}$. Membranes from mature deliveries showed a higher hexosamine content. Of sixty-eight mature membranes, fifty-six $(82 \%)$ had hexosamine values of more than $1 \cdot 21$ $\mathrm{g} / 100 \mathrm{ml}$, while of nineteen premature membranes eleven $(57 \%)$ had such values (see Table 1 ).

The hexosamine contents of membranes correlated negatively with tensile strength. Of membranes with less than $1.20 \mathrm{~g} / 100 \mathrm{ml}$ hexasamine, $58 \%$ had a tensile strength higher than $400 \mathrm{~g} / \mathrm{cm}$. When the hexosamine contents were higher than $1.20 \mathrm{~g} / 100 \mathrm{ml}$, only $19 \%$ had a tensile strength higher than 400 $\mathrm{g} / \mathrm{cm}$ (see Table 2).

\section{TABLE 1}

FOETAL WEIGHT CORRELATED TO HEXOSAMINE CONTENTS

\begin{tabular}{l|c|c|c}
\hline \multirow{2}{*}{ Hexosamine $(g / 100 \mathrm{ml})$} & \multicolumn{2}{|c|}{ Foetal weight $(\mathrm{g})$} & \multirow{2}{*}{ Total } \\
\cline { 2 - 3 } & $<2500$ & $>2501$ & \\
\hline 1.20 or more & 11 & 56 & 67 \\
1.21 or less & 8 & 12 & 20 \\
Total & 19 & 68 & 87 \\
\hline
\end{tabular}

$$
\lambda^{2}(1)=5.01 ; P<0.05 \text {. }
$$

TABLE 2

HEXOSAMINE CONTENT CORRELATED TO TENSILE STRENGTH

\begin{tabular}{l|c|c|c}
\hline \multirow{2}{*}{ Hexosamine $(g / 100 \mathrm{ml})$} & \multicolumn{2}{|c|}{ Tensile strength $(\mathrm{g} / \mathrm{cm})$} & \multirow{2}{*}{ Total } \\
\cline { 2 - 3 } & $<400$ & $>401$ & \\
\hline 1.20 or more & 39 & 9 & 48 \\
1.21 or less & 7 & 10 & 17 \\
Total & 46 & 19 & 65 \\
\hline \multicolumn{2}{|c|}{$\lambda^{2}(l)=9 \cdot 7 ; P<0.01}$.
\end{tabular}

These results agree with an earlier finding that the more mature the membranes, the lower the tensile strength.

\section{Collagen contents}

Collagen determinations were done in a total of sixty-four amniotic membranes, forty from mature and twenty-four from premature deliveries. The levels of collagen varied between 24.6 and $63.9 \mathrm{~g} / 100 \mathrm{ml}$ with a mean value of $43.6 \mathrm{~g} / 100 \mathrm{ml}$.

There was little variation in the values of collagen in relation to foetal weight, but the collagen-hexosamine ratio showed an inverse correlation with foetal weight (see Text-fig. 1). 


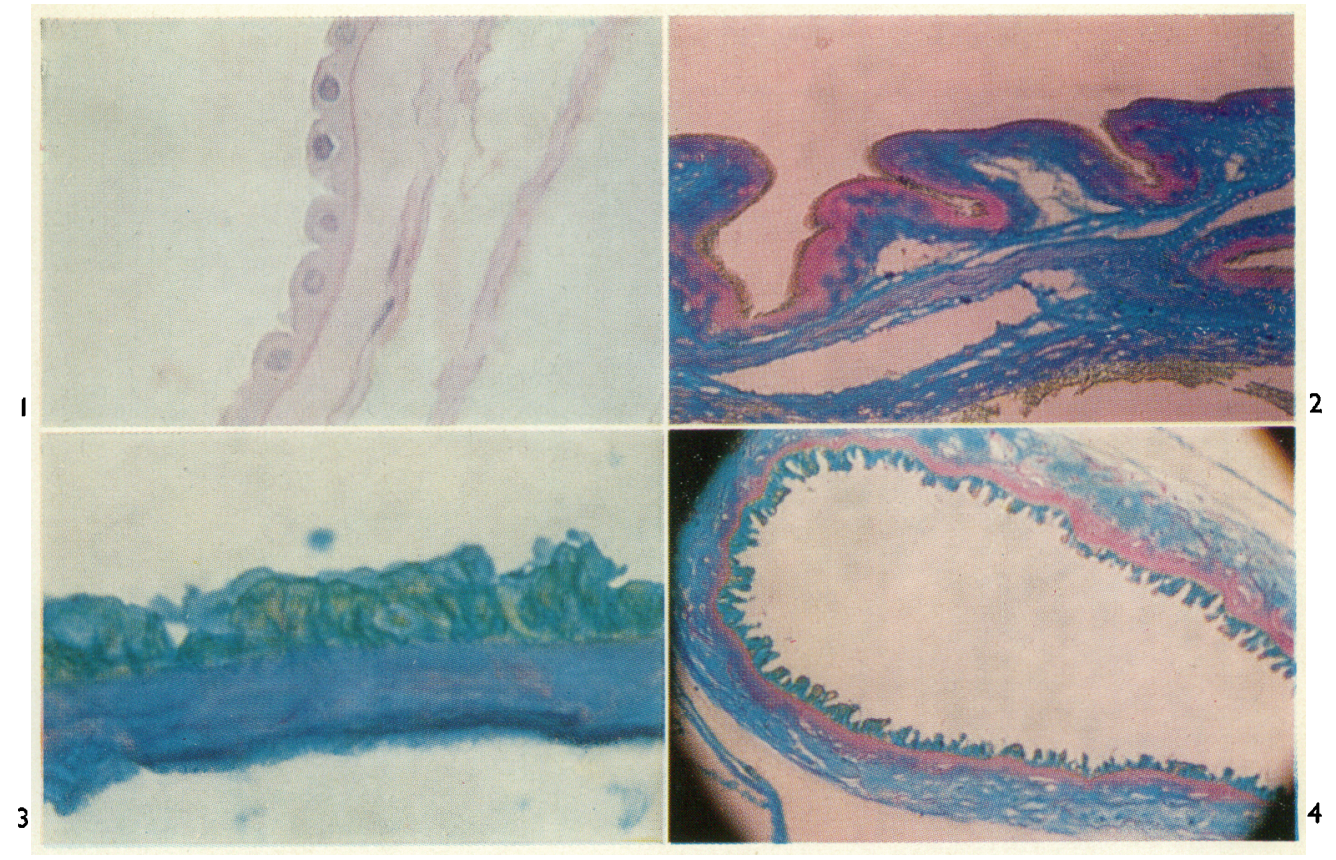

Fic. 1. PAs stain of amniotic membrane; only the basal membrane of the epithelial layer is positively stained. $\times 200$.

FIG. 2. Note alternating subepithelial, stained and unstained, areas. Colloidal iron stain. $\times 50$.

Fig. 3. Subepithelial intensely stained areas. Colloidal iron stain. $\times 200$.

FIG. 4. Note the positive stain of acid mucopolysaccharides in the amniotic epithelium in contrast to the absence in the subepithelial layer, where collagen fibres are abundant. Colloidal iron stain. $\times 50$. 
The higher the foetal weight the smaller the ratio of collagen-hexosamine. There is thus a correlation between the reduction of collagen-hexosamine ratio and the reduction in membrane tensile strength.

\section{DISGUSSION}

Less than $10 \%$ of the total area of the membranes was submitted to the physical, chemical and histological examination and there must therefore be some hesitation in applying the results to cases of premature rupture. The findings seem to be independent of any pathological manifestation and probably represent the changes taking place in the membrane in the process of maturation.

The results indicate that the tensile strength of membranes is gradually diminishing as pregnancy progresses. While hexosamine values and mucopolysaccharide deposits increase with foetal weight, the collagen content does not vary greatly.

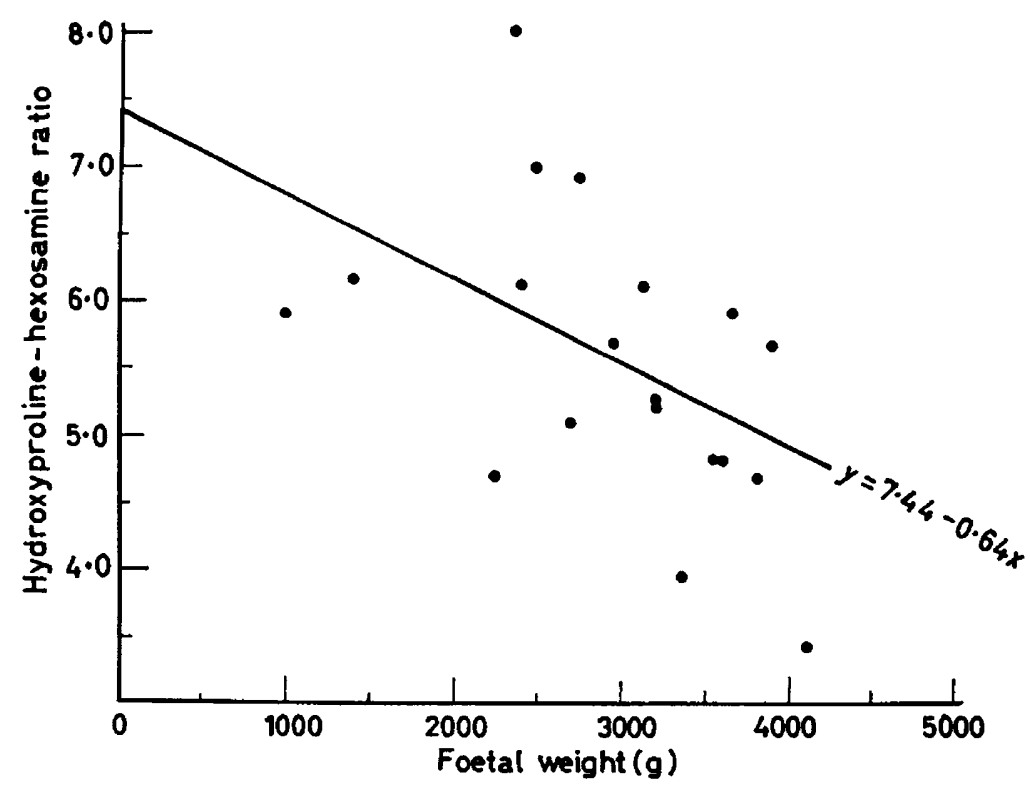

TExT-FIG. 1. Correlation of hydroxyproline-hexosamine ratio with foetal weight.

Ageing of placental membrane is unlikely to be the cause of the chemical and histochemical changes observed. Studies of ageing changes in the aortic and mitral valves, by analogy, have shown a decline of acid mucopolysaccharides in human and bovine heart valves (Angrist, 1964; Hall, 1963; Moretti \& Whitehouse, 1963; Sell \& Scully, 1965). In the membranes both the staining intensity of acid mucopolysaccharides, as well as the hexosamine content increase with 'ageing' of membranes. This may be the expression of the influence of oestrogens on the ground substance (Asboe-Hansen, 1954; Hall, 1963; Rona, 1963).

Collagen content in membranes remains more or less constant while their tensile strength decreases throughout the period of gestation examined. Similar 
results have been reported for the rat membrane (Hall, 1964) whose collagen content remained constant per unit area throughout pregnancy. This fact would indicate that the physical properties of the membranes are not related to the quantity of collagen.

Reduction in membrane tensile strength in our cases was accompanied by a rise in hexosamine values and a constancy in collagen concentration. This would seem to be a physiological change in the behaviour of membrane. It is, as yet, not clear whether the premature rupture of membranes is the expression of a hastened reduction in this collagen-hexosamine ratio.

This consideration does not exclude the possibility that the physical characteristics of the collagen in membranes are the determining factor in their weakening. It has been suggested that proteolytic enzymes (Jung \& Diem, 1959) may be concerned in altering the character and physical properties of the collagen fibres.

The results reported here do not answer the question of why membranes rupture. However, yet unpublished data would seem to indicate that the weakening and premature rupture is an expression of placental dysfunction. It was observed that in cases of toxaemia of pregnancy the rate of premature rupture of membranes is considerably higher than in normal pregnancy. In addition, both our unpublished observations and those reported by Taylor, Bruns \& Drose (1965) indicate low oestriol values in the urine in cases of premature rupture of membranes.

\section{ACKNOWLEDGMENT}

This study was supported by a grant from the National Council for Research and Development, Israel.

\section{REFERENCES}

ANGRIst, A. (1964) Aging heart valves and a unitary pathological hypothesis for sclerosis. F. Geront. 19, 135.

Asboe-Hansen, G. (1954) Connective tissue in health and disease, p. 139. Munksgaard, Copenhagen.

BoAs, N. (1953) Methods for the determination of hexosamines in tissues. F. biol. Chem. 204, 533.

BourNe, G. (1962) The human amnion and chorion, p. 175. Lloyd-Juhe, London.

Halban, J. \& Sertz, L. (1925) Biologie und Pathologie des Weibes, vol. 8, p. 1961. Urban \& Schwartzenberg, Wien.

HaLl, D. A. (1963) International review of connective tissue research, vol. 1, p. 41. Academic Press, New York.

HALI, D. A. (1964) International review of connective tissue research, vol. 2, p. 197, Academic Press, New York.

JAVERT, C. T. (1957) Spontaneous and habitual abortion, p. 97. McGraw-Hill, New York.

Jung, G. \& Diem, R. (1959) Studies on the enzyme content of amniotic fluid. Arch. Gynaek. 192, 155.

KAPLAN, A. L. (1963) Current concepts on premature rupture of the fetal membranes. Bull. Sloane Hosp. Women, 9, 79.

Morettr, A. \& Whitehouse, M. W. (1963) Changes in the mucopolysaccharide composition of bovine heart valves with age. Biochem. $7.87,396$.

Polishuk, W. Z., Ben-Sira, M. Y. \& Kohane, S. (1965) Variations in foetal membrane tensile strength. 7. Obstet. Gynaec. Br. Commonw. 72, 422.

Polishux, W. Z., Kohane, S. \& Hadar, A. (1964) Fetal weight and membrane tensile strength. Am. 7. Obstet. Gynec. 88, 247.

Pozishuk, W. Z., Kohane, S. \& Peranio, A. (1962) The physical properties of fetal membranes. Obstet. Gynec., N.Y. 20, 204. 
Polishuk, W. Z., Kohane, S. \& Wisnitzer, N. (1965) Premature rupture of membranes in different ethnic groups. Israel F. med. Sci. 1, 450.

Rona, G. (1963) The role of vascular mucopolysaccharides in the hemostatic action of estrogens. Am. 7. Obstet. Gynec. 87, 434.

Sell, S. \& Scully, R. E. (1965) Aging changes in the aortic and mitral valves. Histological and histochemical studies with observations on the pathogenesis of calcified aortic stenosis and calcification of the mitral annulus. Am. 7. Path. 46, 345.

Stegemann, H. (1958) Mikrobestimmung von Hydroxyprolin mit Chloramin-T und p-Dimethylaminobenzaldehyd. Hoppe-Seyler's Z. physiol. Chem. 311, 41.

TAylor, E. S., Bruns, P. D. \& Drose, V. E. (1965) Estriol excretion in normal and complicated pregnancies. Clin. Obstet. Gynec. 8, 550.

WOESSNER, J. F., Jr. (1961) The determination of hydroxyproline in tissue and protein samples containing small proportions of this imino acid. Arch. Biochem. Biophys. 93, 440. 